\title{
MicroRNA-154 Expression is Associated With The Prognosis in Non-Small Cell Lung Cancer.
}

Yue Zhao ( $\nabla$ fjueuw@163.com )

Cangzhou Central Hospital https://orcid.org/0000-0001-7826-6456

Xiangjun Kong

Cangzhou Central Hospital

Hongbing Wang

Cangzhou Central Hospital

Primary research

Keywords: MiR-154, NSCLC; Prognosis, Biomarker

Posted Date: July 15th, 2020

DOl: https://doi.org/10.21203/rs.3.rs-41770/v1

License: (1) This work is licensed under a Creative Commons Attribution 4.0 International License.

Read Full License 


\section{Abstract}

Background: MicroRNAs are noncoding RNAs that regulate cellular processes during the progression of tumors. Among various microRNAs, MicroRNA-154 (miR-154) has been reported to be involved in many critical processes of human malignancies. This study aimed to evaluate the significance and prognostic value of miR-154 in human non-small cell lung cancer (NSCLC).

Methods: A total of 144 NSCLC tissues samples and matched non-tumor adjacent tissues specimens were obtained from NSCLC patients and the quantitative real-time PCR (qRT-PCR) was performed to investigate expression levels of miR-154. The correlation between miR-154 expression and survival outcomes of NSCLC patients was performed by Kaplan-Meier analysis, univariate and multivariate analysis.

Results: MiR-154 expression was significantly decreased in NSCLC tissues compared with that in matched non-tumor adjacent tissues $(P<0.001)$. In addition, low expression of miR-154 was demonstrated to be associated with tumors size, TNM stages and distant metastasis of NSCLC patients Survival analysis revealed that patients with low expression of miR-154 showed significantly lower survival rate for OS, DFS and RFS, respectively (all, log rank test, $P<0.001$ ) and miR-154 could be an independent prognostic indicator for NSCLC patients.

Conclusion: The results suggest that miR-154 has the clinical significance in the progression of NSCLC and could be a potential prognostic biomarker for NSCLC patients.

\section{Background}

As a malignant cancer, non-small cell lung cancer (NSCLC) accounts for $85 \%$ of primary lung cancer which is the leading cause of cancer-related deaths worldwide [1,2]. Actually, lung carcinogenesis is a complicated biological process due to mutual dysregulation of different tumor-related genes. Although the treatment including surgery, radiotherapy, and platinum-based combination chemotherapy for NSCLC [3] have improved a lot in recent years, the prognosis of NSCLC remains poor and the five-year survival rate is less than $15 \%[4,5]$. Therefore, it is still urgent to explore precise and special markers for improving the the survival of NSCLC patients.

MicroRNAs (miRNAs, miR) are a class of small (approximately 18-25 nucleotides), single stranded, conserved and noncoding RNAs, which regulate gene expression by binding to the 3 '-untranslated region of specific target messenger RNAs, thereby result in mRNA degradation or translation inhibition [6-8]. It has been widely accepted that miRNAs play an important role in various pathological processes, such as cell proliferation, differentiation, metabolism and apoptosis, indicating their function as suppressor genes or oncogenes $[9,10]$. Currently, increasing numbers of researches have provided that miRNAs are involved in different human malignancies including pancreas cancer, prostate cancer, colorectal cancer and lung cancer [11, 12]. For example, miR-186, miR-205 and miR-21 were all found to promote lung cancer carcinogenesis [13-15]. MiR-154 is also one of the cancer-related miRNAs. Recent studies have reported 
that $m i R-154$ is down-regulated and functions as a candidate tumor suppressor in various cancers, such as hepatocellular carcinoma, colorectal cancer and prostate cancer [16-18]. However, the expression level of miR-154 and weather miR-154 has the clinical significance in NSCLC has not been reported.

Therefore, the aim of the study was to measure the expression level of miR-154 in NSCLC tissues and investigate the correlation of $m i R-154$ level with clinicopathological features as well as the prognostic value of miR-154 in NSCLC patients.

\section{Materials And Methods}

Patients and samples

A total of 144 NSCLC tissue samples and matched non-tumor adjacent tissues specimens were obtained from patients who had pathologically confirmed as NSCLC in Cangzhou Central Hospital. None of the patients had underwent adjuvant treatments including radiotherapy, chemotherapy or immunotherapy before surgical resection. According to the criteria of American Joint Committee on Cancer (AJCC) tumornode-metastasis (TNM) staging system for lung cancer, 35, 20, 33 and 46 specimens exhibited stage I, II, III and IV cancer, respectively. After resection, all tissues were immediately snap-frozen in liquid nitrogen, and then stored at $-80^{\circ} \mathrm{C}$ until RNA extraction. The follow-up was performed after surgery from 2 to 86 months (median: 61.5 months) and clinicopathologic characteristics of patients were summarized in Table 1. The protocol of this study was approved by the Ethical Committee of Cangzhou Central Hospital, and all patients signed the informed consent. 
Table 1

The relationship between miR-154 expression and the clinicopathological characteristics in NSCLC patients

\begin{tabular}{|c|c|c|c|c|}
\hline \multirow[t]{2}{*}{ Variables } & \multirow[t]{2}{*}{$\mathbf{N}$} & \multicolumn{2}{|c|}{ miR-154 expression } & \multirow[t]{2}{*}{$P$ value } \\
\hline & & High & Low & \\
\hline Age & & & & 0.070 \\
\hline$\geqq 55$ & 76 & 31 & 45 & \\
\hline$<55$ & 68 & 38 & 30 & \\
\hline Gender & & & & 0.053 \\
\hline male & 89 & 37 & 52 & \\
\hline female & 55 & 32 & 23 & \\
\hline Tumor size & & & & $0.001^{\star \star}$ \\
\hline$\geqq 3 \mathrm{~cm}$ & 73 & 25 & 48 & \\
\hline$<3 \mathrm{~cm}$ & 71 & 44 & 27 & \\
\hline TNM & & & & $0.003^{\star \star}$ \\
\hline$\bigotimes, \bigotimes$ & 79 & 29 & 50 & \\
\hline$\bigotimes, \bigotimes$ & 65 & 40 & 25 & \\
\hline Lymph node metastasis & & & & 0.216 \\
\hline Absent & 43 & 24 & 19 & \\
\hline Present & 101 & 45 & 56 & \\
\hline Differentiation & & & & 0.076 \\
\hline Well/ moderately & 58 & 33 & 25 & \\
\hline Poorly & 86 & 36 & 50 & \\
\hline Distant metastasis & & & & $0.005^{\star \star}$ \\
\hline Present & 80 & 30 & 50 & \\
\hline Absent & 64 & 39 & 25 & \\
\hline Smoking & & & & 0.064 \\
\hline Yes & 70 & 28 & 42 & \\
\hline No & 74 & 41 & 33 & \\
\hline
\end{tabular}

RNA extraction and quantitative real-time PCR 
Total RNA was isolated from the frozen tissues using TRIzol reagent (Invitrogen) according to the manufacturer's protocol, and then the first cDNA was synthesized using a Reverse Transcription Kit (Takara). QRT-PCR was performed with the Applied Biosystems 7900 Fast Real-Time PCR system (Applied Biosystems, Foster City, CA, USA) to quantify miR-154. U6 was taken as the endogenous control and the sequences of primers were as follows: miR-154, forward 5'-

CGCGAATTCGCATCTAGGACCTCCATCAC-3' and reverse 5'-ACGGGATCCGAACCATCCCTTCACTTACC-3'; U6 forward 5'-CTCGCTTCGGCAGCACA-3' and reverse 5'-AACGCTTCACGAATTTGCGT-3'. The relative expression levels of miR-154 were calculated by $2-\Delta \Delta C t$ method and all experiments were presented in triplicate.

\section{Statistical analysis}

All statistical analyses were conducted using SPSS version 18.0 software (SPSS, Chicago, IL) and GraphPad Prism 5.0 (Graphpad Software Inc.). All quantified variables were presented as mean \pm SD. The Student's $t$ test was used to evaluate the difference between two groups while the differences among three or more groups was evaluated by Chi-square test. Moreover, Kaplan-Meier method with log-rank test was performed to compare survival curves. The analysis of prognostic analysis was carried out using univariate and multivariate Cox proportional hazards model. The difference was significant when a $P$ value $<0.05$.

\section{Results}

The down-regulated expression of miR-154 in NSCLC

We measured the expression levels of miR-154 in 144 samples of NSCLC tissues and matched adjacent specimens by qRT-PCR. As shown in Fig. 1A, miR-154 expression level in NSCLC tissues was significantly lower than those in the corresponding adjacent normal tissues $(0.290 \pm 0.152$ vs $0.725 \pm 0.280, P<0.001)$.

Association between miR-154 expression and clinical features

To analyze whether miR-154 was associated with the development and progression of NSCLC, we divided the samples into high and low miR-154 expression groups according to the mean value of miR-154 levels, and then investigated its relationship with the clinicopathological features. As summarized in Table 1, the significant associations between miR-154 expression and tumor size $(P=0.001)$, TNM $(P=0.003)$ and distant metastasis $(P=0.005)$ were identified. Concretely, low level of miR-154 expression was significantly correlated with larger tumor size ( $\geqq 3 \mathrm{~cm}$ ), TNM stages in III, IV, and present distant metastasis (all, $P<0.001$, Fig. 1B). All these results demonstrated that $m i R-154$ was related to NSCLC progression and it might act as a tumor suppressor. However, no significant relationship had been found between miR-154 expression and other clinical factors including age, gender, lymph node metastasis, differentiation or the or history of smoking.

The correlation between miR-154 level and survival of NSCLC patients 
To further evaluate the correlation between miR-154 expression and clinical outcomes, we determined the prognostic value of miR-154 expression on overall survival (OS), disease-free survival (DFS) and recurrence-free survival (RFS) in NSCLC patients. As determined by Kaplan-Meier method with log rank test, the patients with low expression of $m i R-154$ presented a shorter OS $(P<0.001$; Fig. 2A), shorter DFS $(P<0.001$; Fig. 2B) and shorter RFS $(P<0.001$; Fig. 2C) respectively than those with high miR-154 expression, indicating reduced expression of miR-154 predicted a poor prognosis in patients with NSCLC.

Moreover, as respect to the influence of $m i R-154$ levels and clinicopathological characteristics on patient survival, we performed univariate Cox regression analysis. As shown in Table 2, the tumor size, TNM, lymph node metastasis, distant metastasis and miR-154 expression (all, $P<0.001$ ) were all associated with the OS, DFS and RFS, respectively. Further multivariate analysis indicated that, for NSCLS patients, down-regulated $m i R-154$ level was an independent factor for OS (HR $=2.890,95 \% \mathrm{Cl}, 1.432-5.830 ; P=$ 0.003), DFS (HR $=2.659,95 \% \mathrm{Cl}, 1.347-5.250 ; P=0.005)$ and RFS ( $\mathrm{HR}=11.657,95 \% \mathrm{Cl}, 4.526-30.027 ; P$ $=0.001)$. Furthermore, tumor size were independent factors associated with $\mathrm{OS}(\mathrm{HR}=2.890,95 \% \mathrm{Cl}$, 1.432-5.830; $P=0.003)$ and RFS $(\mathrm{HR}=1.963,95 \% \mathrm{Cl}, 1.216-4.266 ; P=0.016)$, and the TNM could also be an independent factor for OS (HR $=2.659,95 \% \mathrm{Cl}, 1.347-5.250 ; P=0.005)$ and $\mathrm{DFS}(\mathrm{HR}=3.265,95 \%$ $\mathrm{Cl}, 1.895-6.889 ; P=0.001$ ) (Table 3). 
Table 2

Univariate survival analysis of OS, DFS and RFS in patients with NSCLC

\begin{tabular}{|c|c|c|c|c|c|c|}
\hline \multirow[t]{2}{*}{ Variables } & \multicolumn{2}{|l|}{ OS } & \multicolumn{2}{|l|}{ DFS } & \multicolumn{2}{|l|}{ RFS } \\
\hline & $\mathrm{HR}(95 \% \mathrm{Cl})$ & $\begin{array}{l}P \\
\text { value }\end{array}$ & $\mathrm{HR}(95 \% \mathrm{Cl})$ & $\begin{array}{l}P \\
\text { value }\end{array}$ & $\mathrm{HR}(95 \% \mathrm{Cl})$ & $\begin{array}{l}P \\
\text { value }\end{array}$ \\
\hline Age & $\begin{array}{l}1.010(0.515- \\
1.981)\end{array}$ & 0.976 & $\begin{array}{l}1.121(0.612- \\
2.013)\end{array}$ & 0.785 & $\begin{array}{l}1.321(0.845- \\
2.414)\end{array}$ & 0.856 \\
\hline Gender & $\begin{array}{l}1.280(0.672- \\
2.438)\end{array}$ & 0.452 & $\begin{array}{l}1.162(0.712- \\
2.315)\end{array}$ & 0.352 & $\begin{array}{l}1.032(0.456- \\
1.963)\end{array}$ & 0.096 \\
\hline Tumor size & $\begin{array}{l}1.565(0.821- \\
2.983)\end{array}$ & 0.014 & $\begin{array}{l}1.632(0.789- \\
3.025)\end{array}$ & 0.018 & $\begin{array}{l}1.526(0.812- \\
2.856)\end{array}$ & 0.002 \\
\hline TNM & $\begin{array}{l}2.413(1.236- \\
4.713)\end{array}$ & 0.010 & $\begin{array}{l}3.212(1.463- \\
5.426)\end{array}$ & 0.025 & $\begin{array}{l}2.856(1.326- \\
4.632)\end{array}$ & 0.011 \\
\hline $\begin{array}{l}\text { Lymph node } \\
\text { metastasis }\end{array}$ & $\begin{array}{l}2.086(1.078- \\
4.038)\end{array}$ & 0.029 & $\begin{array}{l}2.417(1.123- \\
4.291)\end{array}$ & $<.001$ & $\begin{array}{l}2.621(1.325- \\
4.521)\end{array}$ & 0.006 \\
\hline Differentiation & $\begin{array}{l}2.900(1.432- \\
5.876)\end{array}$ & 0.003 & $\begin{array}{l}1.890(1.263- \\
4.215)\end{array}$ & 0.008 & $\begin{array}{l}2.236(1.365- \\
5.026)\end{array}$ & $\begin{array}{l}<.001 \\
0.001\end{array}$ \\
\hline $\begin{array}{l}\text { Distant } \\
\text { metastasis }\end{array}$ & $\begin{array}{l}1.145(0.603- \\
2.173)\end{array}$ & 0.019 & $\begin{array}{l}1.256(0.732- \\
2.653)\end{array}$ & $<.001$ & $\begin{array}{l}1.026(0.589- \\
2.036)\end{array}$ & 0.035 \\
\hline Smoking & $\begin{array}{l}1.783(0.920- \\
3.457)\end{array}$ & 0.087 & $\begin{array}{l}1.235(0.856- \\
3.647)\end{array}$ & 0.052 & $\begin{array}{l}1.426(0.889- \\
3.212)\end{array}$ & 0.126 \\
\hline miR-154 level & $\begin{array}{l}8.108(3.398- \\
19.345)\end{array}$ & $<.001$ & $\begin{array}{l}9.632(3.536- \\
20.168)\end{array}$ & $<.001$ & $\begin{array}{l}9.256(3.126- \\
19.563)\end{array}$ & $\begin{array}{l}<.001 \\
0.001\end{array}$ \\
\hline
\end{tabular}

Table 3

Multivariate survival analysis of OS, DFS and RFS in patients with NSCLC

\begin{tabular}{|c|c|c|c|c|c|c|}
\hline \multirow[t]{2}{*}{ Variables } & \multicolumn{2}{|l|}{ OS } & \multicolumn{2}{|l|}{ DFS } & \multicolumn{2}{|l|}{ RFS } \\
\hline & $\mathrm{HR}(95 \% \mathrm{Cl})$ & $\begin{array}{l}P \\
\text { value }\end{array}$ & HR (95\% Cl) & $\begin{array}{l}P \\
\text { value }\end{array}$ & $\mathrm{HR}(95 \% \mathrm{Cl})$ & $\begin{array}{l}P \\
\text { value }\end{array}$ \\
\hline $\begin{array}{l}\text { Tumor } \\
\text { size }\end{array}$ & $\begin{array}{l}2.890(1.432- \\
5.830)\end{array}$ & 0.003 & - & - & $\begin{array}{l}1.963(1.216- \\
4.266)\end{array}$ & 0.016 \\
\hline TNM & $\begin{array}{l}2.659(1.347- \\
5.250)\end{array}$ & 0.005 & $\begin{array}{l}3.265(1.895- \\
6.889)\end{array}$ & 0.001 & - & - \\
\hline $\begin{array}{l}\text { miR-154 } \\
\text { level }\end{array}$ & $\begin{array}{l}11.657(4.526- \\
30.027)\end{array}$ & $<.001$ & $\begin{array}{l}9.123(3.217- \\
28.132)\end{array}$ & $<.001$ & $\begin{array}{l}12.163(4.521- \\
31.263)\end{array}$ & $\begin{array}{l}< \\
0.001\end{array}$ \\
\hline
\end{tabular}

\section{Discussion}


As the most common malignant disease in the world, lung cancer is the leading cause of mortality in China [19] According to the past researches, several prognostic factors and biomarkers for NSCLC have been identified [20-23], which have improved the outcome of the NSCLC patients. However, the 5-year survival rate for the NSCLC is still unsatisfactory. Therefore, it is still urgent to identify novel and reliable prognostic markers to improve the prognosis of NSCLC patients.

Previous researches reveal that, till now, approximately 1,900 human miRNAs have been identified [7], which have great importance in the regulation of gene expression by regulating cellular functions such as proliferation, apoptosis and differentiation [24, 25]. Additionally, the roles of miRNAs in the progression and tumorigenesis of lung cancer have been gradually recognized. miR-10b in lung cancer is closely associated with lymph node metastasis [26]. Moreover the abnormal expression of several miRNAs are found to be involved in lung cancer [27-29]. For example, Foss et al. reported that the expression of miR1254 and miR-574-5p was significantly increased in the early-stage of NSCLC samples and they may serve as valuable biomarkers for NSCLC early detection [27]. Jia et al. have demonstrated that the miR146a expression was significantly decreased in NSCLC patients [28]. In addition, the study of Nasser et al. found that miR-1 was down-regulated in human primary lung cancer tissues and cell lines and it has potential therapeutic application against lung cancers [29].

MiR-154 is located on human chromosome 14q32, which is frequently lost in human cancers [30, 31]. According to recent studies, miR-154 has been reported to be down-regulated in various types of cancer tissues, and closely associated with the outcome of prognosis for several tumors. For instance, Pang et al. showed that miR-154 functioned as a tumor suppressor in hepatocellular carcinoma by targeting ZEB2 and it may serve as a potential target for HCC [16]. Yang et al. indicated that low expression of miR154 was associated with tumor progression of colorectal cancer and it may be an independent prognostic marker for CRC patient [17]. Moreover, Zhu et al. reported that miR-154 expression significantly decreased in primary prostate cancer samples and played a prominent role in prostate cancer proliferation by suppressing CCND2 [18]. However, the clinical significance of miR-154 in lung cancer are poor characterized.

In the present study, we explored the expression of miR-154 and its clinical value in predicting survival outcome in patients with NSCLC. The results confirmed that the miR-154 expression was significantly down-regulated in NSCLC tissues compared to the adjacent normal specimens. Subsequently, the association between miR-154 expression levels and clinicopathological characteristics in NSCLC revealed that down-regulation of miR-154 was closely correlated with tumor size, TNM stage and distant metastasis. In contrast, there was no correlation between miR-154 expression and age, gender, lymph node metastasis, differentiation or smoking history. All these results suggest that $m i R-154$ plays an important role in the progression of NSCLC. Moreover, survival analysis revealed that patients with low miR-154 expression have worse survival outcome. This result is consistent with report examining the prognostic role of miR-154 [17]. According to multivariate analyses, miR-154 was an independent prognostic factor for OS, DFS and RFS. 
This present study had several limitations. First, the sample size was relatively small. Secondly, the underlying mechanisms of miR-154 in NSCLC have not been well characterized. Therefore, identification of miR-154 function and its downstream genes in lung cancer would be an important goal in future studies.

\section{Conclusions}

In conclusion, in the present study, we explored that the expression of miR-154 was down-regulated in NSCLC, and the patients with low miR-154 expression had shorter survival time in the OS, DFS and RFS analysis than those with high miR-154 expression. All these findings demonstrated that miR-154 could be regarded as an independent prognostic factor for patients with NSCLC.

\section{Abbreviations}

MicroRNA-154 (miR-154)

non-small cell lung cancer (NSCLC)

quantitative real-time PCR (qRT-PCR)

MicroRNAs (miRNAs, miR)

American Joint Committee on Cancer (AJCC)

tumor-node-metastasis (TNM)

overall survival (OS)

disease-free survival (DFS)

recurrence-free survival (RFS)

\section{Declarations}

\section{Ethics approval and consent to participate}

This study was supported by the Ethics Committee of Cangzhou Central Hospital and also has been carried out in accordance with the World Medical Association Declaration of Helsinki.

The subjects had been informed the objective. Certainly, written consents were signed by every subject in this study.

\section{Consent for publication}

We obtaining permission from participants to publish their data. 
Availability of data and materialsData sharing is not applicable to this article as no datasets were generated or analysed during the current study.

Competing interestsThe authors declare that they have no competing interests.

Funding Not applicable.

Authors' contributions Y.Z. design of the work; Y.Z. the acquisition, analysis, Y.Z. interpretation of data; X.K. the creation of new software used in the work; H.W. have drafted the work or substantively revised it. All authors read and approved the final manuscript.

Acknowledgements Not applicable.

\section{References}

1. Buyukcelik A, Yalcin B, Utkan G. Multidisciplinary management of lung cancer. N Engl J Med. 2004;350(19):2008-10. author reply 2008-2010.

2. Siegel R, Naishadham D, Jemal A. Cancer statistics, 2012. Cancer J Clin. 2012;62(1):10-29.

3. Ettinger DS, Akerley W, Borghaei H, Chang AC, Cheney RT, Chirieac LR, D'Amico TA, Demmy TL, Govindan R, Grannis FW, Jr. et al: Non-small cell lung cancer, version 2.2013. Journal of the National Comprehensive Cancer Network: JNCCN2013, 11(6):645-653; quiz 653.

4. Siegel R, Naishadham D, Jemal A. Cancer statistics, 2013. Cancer J Clin. 2013;63(1):11-30.

5. da Cunha Santos G, Shepherd FA, Tsao MS. EGFR mutations and lung cancer. Annual review of pathology. 2011;6:49-69.

6. Krol J, Krzyzosiak WJ. Structure analysis of microRNA precursors. Methods Mol Biol. 2006;342:1932.

7. Esteller M. Non-coding RNAs in human disease. Nature reviews Genetics. 2011;12(12):861-74.

8. Wienholds E, Plasterk RH. MicroRNA function in animal development. FEBS Lett. 2005;579(26):5911-22.

9. Esquela-Kerscher A, Slack FJ. Oncomirs - microRNAs with a role in cancer. Nature reviews Cancer. 2006;6(4):259-69.

10. Chen F, Hu SJ. Effect of microRNA-34a in cell cycle, differentiation, and apoptosis: a review. J Biochem Mol Toxicol. 2012;26(2):79-86.

11. Catto JW, Alcaraz A, Bjartell AS, De Vere White R, Evans CP, Fussel S, Hamdy FC, Kallioniemi O, Mengual L, Schlomm T, et al. MicroRNA in prostate, bladder, and kidney cancer: a systematic review. European urology. 2011;59(5):671-81.

12. Mazeh H, Mizrahi I, llyayev N, Halle D, Brucher B, Bilchik A, Protic M, Daumer M, Stojadinovic A, Itzhak $A$, et al. The Diagnostic and Prognostic Role of microRNA in Colorectal Cancer - a Comprehensive review. J Cancer. 2013;4(3):281-95. 
13. Cui G, Cui M, Li Y, Liang Y, Li W, Guo H, Zhao S. MiR-186 targets ROCK1 to suppress the growth and metastasis of NSCLC cells. Tumour biology: the journal of the International Society for Oncodevelopmental Biology Medicine. 2014;35(9):8933-7.

14. Larzabal L, de Aberasturi AL, Redrado M, Rueda P, Rodriguez MJ, Bodegas ME, Montuenga LM, Calvo A. TMPRSS4 regulates levels of integrin alpha5 in NSCLC through miR-205 activity to promote metastasis. British journal of cancer. 2014;110(3):764-74.

15. Zhang JG, Wang JJ, Zhao F, Liu Q, Jiang K, Yang GH. MicroRNA-21 (miR-21) represses tumor suppressor PTEN and promotes growth and invasion in non-small cell lung cancer (NSCLC). Clin Chim Acta. 2010;411(11-12):846-52.

16. Pang X, Huang K, Zhang Q, Zhang Y, Niu J. miR-154 targeting ZEB2 in hepatocellular carcinoma functions as a potential tumor suppressor. Oncol Rep. 2015;34(6):3272-9.

17. Kai Y, Qiang C, Xinxin P, Miaomiao Z, Kuailu L. Decreased miR-154 expression and its clinical significance in human colorectal cancer. World J Surg Oncol. 2015;13:195.

18. Zhu C, Shao P, Bao M, Li P, Zhou H, Cai H, Cao Q, Tao L, Meng X, Ju X, et al. miR-154 inhibits prostate cancer cell proliferation by targeting CCND2. Urol Oncol. 2014;32(1):31 e39-16.

19. Siegel R, Ma J, Zou Z, Jemal A. Cancer statistics, 2014. Cancer J Clin. 2014;64(1):9-29.

20. Liang W, Zhang L, Jiang G, Wang Q, Liu L, Liu D, Wang Z, Zhu Z, Deng Q, Xiong X, et al. Development and validation of a nomogram for predicting survival in patients with resected non-small-cell lung cancer. Journal of clinical oncology: official journal of the American Society of Clinical Oncology. 2015;33(8):861-9.

21. Kasapoglu US, Arinc S, Gungor S, Irmak I, Guney P, Aksoy F, Bandak D, Hazar A: Prognostic factors affecting survival in non-small cell lung carcinoma patients with malignant pleural effusions. The clinical respiratory journal 2015.

22. Spigel DR, Patel JD, Reynolds CH, Garon EB, Hermann RC, Govindan R, Olsen MR, Winfree KB, Chen J, Liu J, et al: Quality of life analyses from the randomized, open-label, phase III PointBreak study of pemetrexed-carboplatin-bevacizumab followed by maintenance pemetrexed-bevacizumab versus paclitaxel-carboplatin-bevacizumab followed by maintenance bevacizumab in patients with stage IIIB or IV nonsquamous non-small-cell lung cancer. Journal of thoracic oncology: official publication of the International Association for the Study of Lung Cancer 2015, 10(2):353-359.

23. Berghmans T, Ameye L, Lafitte JJ, Colinet B, Cortot A, CsToth I, Holbrechts S, Lecomte J, Mascaux C, Meert AP, et al. Prospective Validation Obtained in a Similar Group of Patients and with Similar High Throughput Biological Tests Failed to Confirm Signatures for Prediction of Response to Chemotherapy and Survival in Advanced NSCLC: A Prospective Study from the European Lung Cancer Working Party. Frontiers in oncology. 2014;4:386.

24. He L, Hannon GJ. MicroRNAs: small RNAs with a big role in gene regulation. Nature reviews Genetics. 2004;5(7):522-31.

25. Mendell JT. MicroRNAs: critical regulators of development, cellular physiology and malignancy. Cell Cycle. 2005;4(9):1179-84. 
26. Roth C, Kasimir-Bauer S, Pantel K, Schwarzenbach H. Screening for circulating nucleic acids and caspase activity in the peripheral blood as potential diagnostic tools in lung cancer. Molecular oncology. 2011;5(3):281-91.

27. Foss KM, Sima C, Ugolini D, Neri M, Allen KE, Weiss GJ. miR-1254 and miR-574-5p: serum-based microRNA biomarkers for early-stage non-small cell lung cancer. Journal of thoracic oncology: official publication of the International Association for the Study of Lung Cancer. 2011;6(3):482-8.

28. Jia Y, Zang A, Shang Y, Yang H, Song Z, Wang Z, Ren L, Wei Y, Hu L, Shi H, et al. MicroRNA-146a rs2910164 polymorphism is associated with susceptibility to non-small cell lung cancer in the Chinese population. Med Oncol. 2014;31(10):194.

29. Nasser MW, Datta J, Nuovo G, Kutay H, Motiwala T, Majumder S, Wang B, Suster S, Jacob ST, Ghoshal K. Down-regulation of micro-RNA-1 (miR-1) in lung cancer. Suppression of tumorigenic property of lung cancer cells and their sensitization to doxorubicin-induced apoptosis by miR-1. J Biol Chem. 2008;283(48):33394-405.

30. Pecuchet N, Popova T, Manie E, Lucchesi C, Battistella A, Vincent-Salomon A, Caux-Moncoutier V, Bollet M, Sigal-Zafrani B, Sastre-Garau X, et al. Loss of heterozygosity at $13 q 13$ and $14 q 32$ predicts BRCA2 inactivation in luminal breast carcinomas. International journal of cancer Journal international du cancer. 2013;133(12):2834-42.

31. Manodoro F, Marzec J, Chaplin T, Miraki-Moud F, Moravcsik E, Jovanovic JV, Wang J, lqbal S, Taussig D, Grimwade $D$, et al. Loss of imprinting at the $14 q 32$ domain is associated with microRNA overexpression in acute promyelocytic leukemia. Blood. 2014;123(13):2066-74.

\section{Figures}
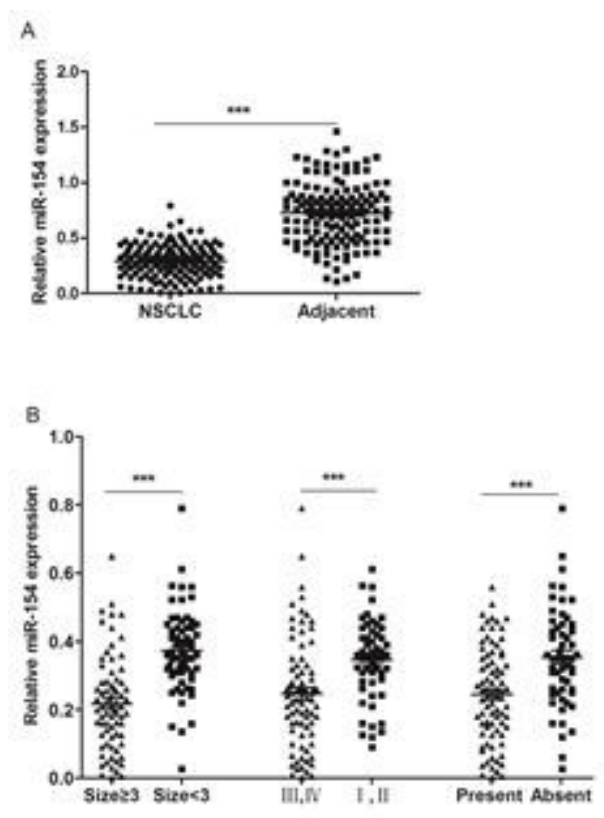

\section{Figure 1}


Analysis of miR-154 expression in NSCLC tissues. (A) Relative expression of miR-154 in NSCLC tissues was significantly decreased compared with that in corresponding non-tumor tissues $(P<0.001)$. (B) miR154 expression was significantly lower in patients with advanced tumor size (size $\geq 3$ ), high TNM stage (stage $\mathbb{\nabla}$, ) and present distant metastasis.
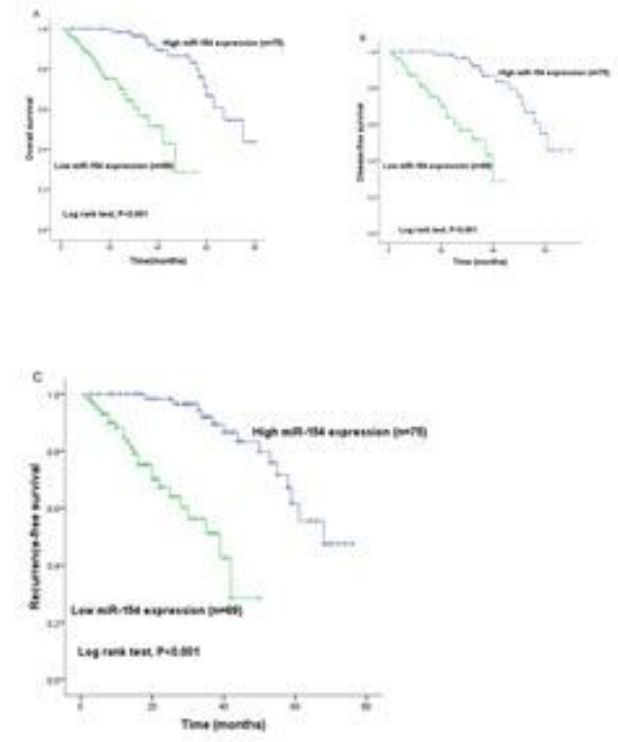

Figure 2

Survival analysis. The patients with low miR-154 expression had shorter overall survival (OS, $P<0.001 ; A)$ disease-free survival (DFS, $P<0.001 ; B$ ) and recurrence-free survival (RFS, $P<0.001 ; C$ ) than patients with high miR-154 expression. 